\title{
Springer
}

\section{SPRINGER NATURE}

A Fast and Less Expensive Test to Determine PermeabilityRelated Parameters on Well's Drilled Cuttings

M. Ludovico-Marques (1)

1. Barreiro School of Technology, Polytechnic Institute of Setúbal, Portugal 


\section{Motivation / Goals}

Permeability tests are time consuming and/or expensive

Fast methodologies to determine permeability-related parameters on drilled cuttings and cores from wells are very helpful tools

Proposal of another methodology of absorption tests on sandstone drilled cuttings and cores into practice of Oil \& Gas exploration

Range of sandstone permeability-related properties supporting fast test's procedures

Lithotypes of Lourinhã Formation analog $\rightarrow$ Statfjord Formation in North Sea

Improve knowledge (I\&D) 
Today's presentation

1. Introduction

2. Experimental Program

3. Experimental Results

4. Analysis of Experimental Results

5. Conclusions 


\section{Introduction}

- Sandstone strata (main rocks of Lourinhã Formation), thickness up to 900 m (early Tithonian and Late Kimmeridgian)

- Stratigraphy and tectonics studies (Martinius and Gowland, 2011; Taylor et al, 2014)

- Samples collected from Lourinhã Formation analog $\rightarrow$ mineralogical and physical properties data

- Fast RILEM test carried out on sandstone specimens and also on drilled cuttings and cores, to evaluate permeability-related parameters

- Correlation to well logs, e.g. density, gamma ray, neutron, nuclear magnetic resonance, spontaneous potential, electrical resistivity and sonic

- Samples cleaned off oil using Soxhlet extraction methodology and dried

- Results in a faster way on rocks (higher open porosity values) in comparison to traditional laboratory methods 


\section{Experimental program}

- Samples collected from sandstone outcrops

- Thin section observations (EN12407)

- Petrographic polarizing microscope $\rightarrow$ point counting method: modal analysis

- Blocks of M variety were cut in 140 cubic (2 in.-long) and prismatic samples ( 2 in.-long on cross section and a length of $4 \mathrm{in}$.)

- Porosity and density of sandstone samples by hydrostatic weighing and Archimedes principle (RILEM and EN1936)

- Mercury Intrusion Porosimetry (MIP)

- Pore size distribution

- Permeability inferred (Katz and Thompson method) 


\section{Experimental program}

- RILEM's Water absorption under low pressure (Karsten tube)

- Height of water $(0.322 \mathrm{ft})$ and a volume $\left(1.41 \times 10^{-4} \mathrm{ft}^{3}\right)$

- Four graduation lines (maximum scale), each: $3.53 \times 10^{-5} \mathrm{ft}^{3}$

- Lower graduation scale: $3.53 \times 10^{-6} \mathrm{ft}^{3}$

- Water fills vertical tube from the upper opening up to the graduation " 0 "

- Sealed on sample surface by a removable putty

- Graphs of water absorption: $\Delta \mathrm{m} / \mathrm{S}^{2}$ (vertical axis) and Vt (bottom axis)

- Slope of the linear part $\rightarrow$ Water absorption coefficient $\left(\mathrm{lb} / \mathrm{ft}^{2} \mathrm{Vh}\right)$ 


\section{Experimental Results}

- Mineralogical characterization

- Two lithotypes of sandstones $(A+B, C+M)$

- Lithic arkose with carbonate cement (Folk, 1974)

- Lithotype A + B: 34-40\% carbonates and 30-32\% quartz

- Lithotype C + M: 20-25\% carbonates and 40-51\% quartz

- All these lithotypes: $4-6 \%$ of minerals of mica

- Physical characterization

- Open porosity: $3.6 \%(\mathrm{~A})$ to $12.7 \%$ (C) and $18.5 \%(\mathrm{M})$

- Bulk density (M): $446.5 \mathrm{lb} / \mathrm{ft}^{3}$

- Microporosity (M): 75\%

- Median pore radius (M): $3.6 \mu \mathrm{m}$ (50\% volume of mercury injection)

- Permeability (M): 20 to 30 mD (Katz and Thompson method) 


\section{Experimental Results}

- Physical characterization (continuation)

- Water absorption (Karsten Pipe method)

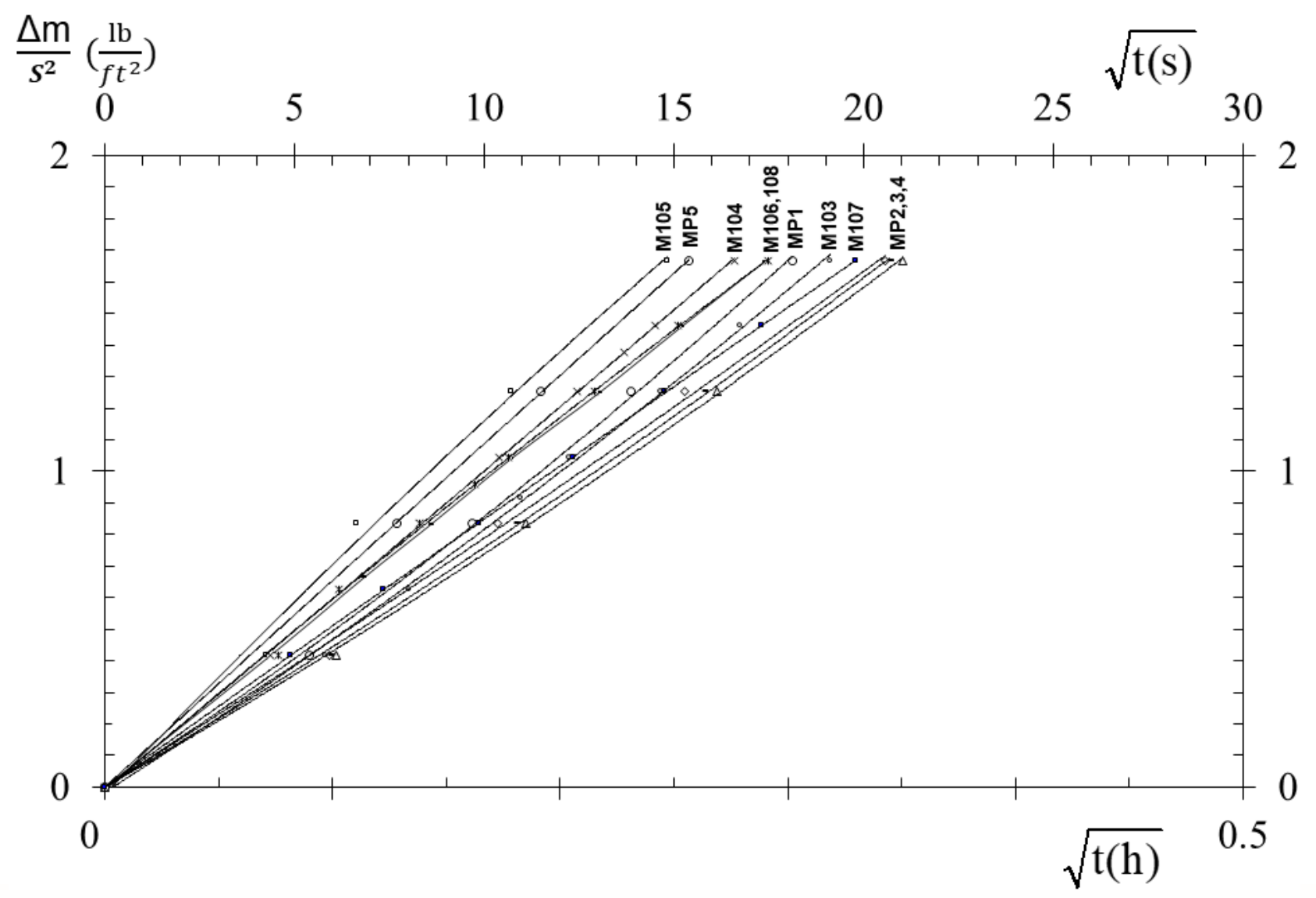




\section{Experimental Results}

- Physical characterization (continuation)

\begin{tabular}{lll}
\hline Samples & $\begin{array}{l}\text { Coefficient of water absorption, } \mathrm{k} \\
\left(\mathrm{lb} / \mathrm{ft}^{2} \sqrt{\mathrm{h}}\right)\end{array}$ & $\begin{array}{l}\text { Coefficient of water } \\
\text { absorption, } \mathrm{k} \\
\left(\mathrm{lb} / \mathrm{ft}^{2} \sqrt{\mathrm{h}}\right) \\
\text { Average } \pm \mathrm{SD}(\mathrm{CV} \%)\end{array}$ \\
\hline MP1 & 5.4 & \\
MP2 & 4.8 & \\
MP3 & 4.7 & \\
MP4 & 4.8 & $5.5 \pm 0.7(12.7 \%)$ \\
MP5 & $6.5^{*}$ & $5.3 \pm 0.5(9.4 \%)^{*}$ \\
M103 & 5.1 & \\
M104 & 6.0 & \\
M105 & $6.9^{*}$ & \\
M106 & 5.8 & \\
M107 & 5.1 & \\
M108 & 5.8 & \\
\hline
\end{tabular}

*Without higher values.

- Coefficient of water absorption, $\mathrm{k}_{\text {average }}(\mathrm{M}): 5.3 \mathrm{lb} / \mathrm{ft}^{2} \mathrm{Vh}(\mathrm{C} . \mathrm{V} .<10 \%)$ 


\section{Analysis of Experimental Results}

- M variety samples of Lourinhã Formation, lithic arkose with carbonate cement

- Open porosity: $18.5 \pm 0.4 \%$

- Permeability: 20-30 mD.

- Water absorption coefficient under low pressure: $5.3 \pm 0.5 \mathrm{lb} / \mathrm{ft}^{2} \mathrm{Vh}$

- Siliciclastic world reservoirs with Median porosity statistical class of 17.5-22.5\%, average permeability of $18 \mathrm{mD}$ (Ehrenberg and Nadeau, 2005)

- Similar average values to these values are shown by samples of Sandstone M variety

- Permeability $(\mathrm{mD})$ is 4-5 times higher than the water absorption coefficient ( $\mathrm{lb} / \mathrm{ft}^{2} \mathrm{Vh}$ )

- This test procedures, only several minutes or even seconds on rocks with open porosity higher than $15 \%$

- Permeability from Mercury Intrusion Porosimetry took at least half a day

- Air permeability from steady state or transient pulse methods took similar times in comparison to RILEM method, but with much more expensive equipment 


\section{Conclusions}

- This study aimed to propose another methodology of permeability-related tests on sandstone drilled cuttings and cores into Oil \& Gas exploration practice

- Mineralogical and physical characterization of lithotypes's samples collected from Lourinhã Formation (analog of Statfjord Formation) was performed

- Based on experimental results, a practical correlation between permeability (mD) and the permeability-related RILEM's water absorption coefficient ( $\left.\mathrm{lb} / \mathrm{ft}^{2} \mathrm{~V} \mathrm{~h}\right)$ was obtained on these rocks

- The procedures of this RILEM's test are faster than other permeability tests and/or require less expensive equipments

- Based on this study contribution, Karsten pipe absorption test would be widespread recommended to Oil \& Gas exploration on rocks porosity higher than 15\%

- Further research should be carried out 


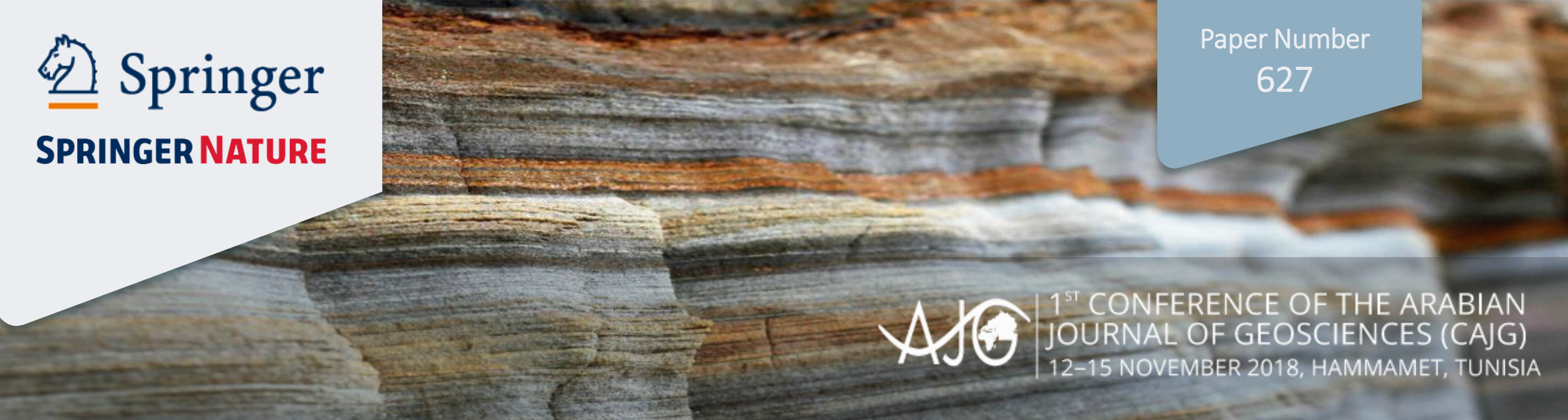

Thank you!

Marco Ludovico-Marques

marco.marques@estbarreiro.ips.pt 